\title{
The possible alleviating effect of garlic supplement on the neural retina in a rat model of hypercholesterolemia: A histological and immunohistochemical study
}

\author{
Eetmad A. Arafat, ${ }^{1}$ Eman M.I. Youssef, ${ }^{2,3}$ Hanaa A. Khalaf ${ }^{1}$ \\ ${ }^{1}$ Histology and Cell Biology Department, Faculty of Medicine, Mansoura University, Mansoura, Egypt \\ ${ }^{2}$ Department of Biochemistry, Faculty of Medicine, Al-Azhar University, Cairo, Egypt \\ ${ }^{3}$ Department of Biochemistry, College of Medicine, Taif University, Taif, Saudi Arabia
}

\begin{abstract}
The purpose of this work was to prove that oxidative stress is the main mechanism responsible for retinal neurodegenerative changes, subsequent apoptosis, and inflammatory cytokine release in rats fed with a high cholesterol diet (HCD) and determine the role of garlic in alleviating these changes. Forty rats were equally divided into four groups: control, garlic-treated (positive control), HCD, and HCD + garlic-treated (HCD + G). By the end of the experiment ( 24 weeks) blood samples were collected for assessment of serum lipid profile, oxidative stress parameters, and plasma levels of IL- 6 and TNF- $\alpha$. Both eyes of the rats were enucleated; one was used for light microscopic examination and the other for electron microscopic examination. There was a significant increase in the levels of serum lipids, oxidative stress parameters, IL- 6 and TNF- $\alpha$, and area of expression of caspase-3 in the HCD group compared to both the control and HCD + G groups. Histological examination revealed degenerative changes in all layers of the neural retina in the HCD group. Garlic administration resulted in a significant improvement in the biochemical, immunohistochemical, and histological characteristics of hypercholesterolemic rats. These findings support the hypotheses that garlic has strong antioxidant, anti-apoptotic, and anti-inflammatory properties. Garlic ameliorates the neurodegenerative changes in the neural retina of hypercholesteremic rats.
\end{abstract}

Key words: Hypercholesterolemia; garlic; neural retina.

Correspondence: Eetmad A. Arafat, Histology and Cell Biology Department, Faculty of Medicine, Mansoura University, Mansoura, Egypt. E-mail: arafateetmad@gmail.com

Contributions: EAA, HAK, designed the research work, conduct the histological practical part, wrote the first draft, interpretation of data; EMIY, performed the statistical analysis and the biochemical practical part. All authors read and approved the final version of the manuscript.

Conflict of interest: The authors declare that they have no conflict of interest.

Ethical approval: Rats were treated in accordance with the institutional procedures for animal care and use of laboratory animals Faculty of Medicine, Mansoura University. The experimental protocols and procedures were approved by the institutional review board (IRB) (Ref R. 2003759).

Funding: This research did not receive any specific grant.

Availability of data and materials: The data will be available upon request from the corresponding author. 


\section{Introduction}

The modern lifestyle is associated with frequent intake of fast food, which is a high-fat diet, and reduced exercise, both of which are factors that may result in obesity, hypercholesteremia, and systemic diseases in individuals. ${ }^{1}$

Although dietary intake remains the main source of cholesterol, it can be synthesized endogenously by the liver and other tissues. ${ }^{2}$ Cholesterol plays a vital role in vitamin D synthesis, bile acid metabolism, and steroid hormone formation. ${ }^{3}$

Cholesterol is considered the chief sterol in the retina. It is extensively found within the neural retinal cell layers. Cholesterol transport is vital as it supplies retinal neurons with the lipids required for the preservation and restoration of their cell membranes. ${ }^{4}$ Interestingly, the retinal pigmented epithelium, and probably Müller cells of the retina, contain low density lipoprotein (LDL) receptors that can uptake circulating LDL. The regulation of cholesterol metabolism is accomplished via neuronal and glial cell interaction. ${ }^{5}$ Cholesterol homeostasis is essential in maintaining the proper structure and function of the retina. ${ }^{6}$

Hyperlipidemia, which is a modifiable risk factor, causes atherosclerosis and other related diseases. ${ }^{7}$ It has been proven that both decreased and increased cellular cholesterol levels are trademarks of neurodegenerative retinal and brain diseases, respectively. ${ }^{8}$ Previous reports have also shown that hypercholesterolemia enhances the retinal expression of nitric oxide (NO) synthase 2, which causes lipid peroxidation, leading to retinal oxidative damage. $^{9}$

Garlic (Allium sativum L.) has attained a special place in the traditional medicine of many cultures. It has also acquired importance in modern medicine due to its various health benefits. Garlic has been used in the treatment of cardiovascular diseases, ${ }^{10}$ hypertension, ${ }^{11}$ and atherosclerosis. ${ }^{12}$ It also reduces the risk for cancer, enhances immune function, and has hepatoprotective and antimicrobial functions. ${ }^{13}$ In addition, it possesses antioxidant properties. ${ }^{14}$ The antioxidant effects of garlic could be due to its ability to enhance numerous antioxidant enzymes that protect endothelial cells against oxidative stress ${ }^{15}$ and scavenge intracellular reactive oxygen species (ROS).. ${ }^{16}$

Garlic exerts its anti-inflammatory actions through inhibition of various inflammatory mediators, such as NO, prostaglandin E2 , tumor necrotizing factor (TNF)- $\alpha$, and interleukin (IL)-1 $\beta{ }^{17}$

Prophylactic administration of garlic decreased serum levels of total cholesterol (TC), triglycerides (TG), and LDL cholesterol (LDL-C), and increased serum high-density lipoprotein cholesterol (HDL-C) levels. The beneficial effects of garlic in hypercholesteremic states have been reported in humans ${ }^{18}$ and experimental animals. ${ }^{19}$

The mechanism by which garlic improves cholesterol level is conducted by allicin components in garlic, which decrease cholesterol absorption and biosynthesis. ${ }^{20}$ Garlic has been proven to decrease LDL-C levels through inhibition of hepatic enzymes involved in LDL-C synthesis, such as $7 \alpha$-hydroxylase and HMGCoA reductase, and increasing bile acid excretion. ${ }^{21}$ Furthermore, garlic significantly enhances excretion of bile salts in feces and mobilization of tissue lipids into the circulation. ${ }^{22}$

Recently, research has focused on the use of natural products in the prevention and treatment of diseases. Since garlic is cheap and widely available, it has the potential to be used in alternative medicine. The purpose of this work was to study oxidative stress and inflammatory cytokines in rats fed with a high cholesterol diet (HCD) and their correlation to the histological changes in the neural retina as well as to elucidate the possible role of garlic supplementation in the diet.

\section{Materials and Methods}

\section{Drugs}

Garlic extract (Tomex) (ATOS pharma, Sekem Group, Cairo, Egypt) was obtained in the form of enteric-coated tablets. Each tablet contained $200 \mathrm{mg}$ of dried garlic powder. The tablets were then dissolved in a physiological saline solution. Tomex contains concentrated garlic powder prepared from garlic grown without the use of chemical fertilizers or pesticides.

\section{Experimental hypercholesterolemia}

Hypercholesterolemia was induced by feeding rats with a diet containing $4 \%$ cholesterol, $1 \%$ cholic acid, and $0.5 \%$ thiouracil for 24 weeks. $^{23,24}$

\section{Animals and experimental design}

Forty adult male Sprague-Dawley rats weighing 140-160 g were obtained from the animal house at the Faculty of Pharmacy, Mansoura University, Egypt. The rats were housed under controlled environmental conditions $\left(24^{\circ} \mathrm{C}\right.$, a 12 -h light/dark cycle, and $40-60 \%$ humidity) for a one-week acclimation period. The rats were allowed free access to water and standard rat diet during this period. The rats were then equally divided into four groups (10 rats each):

- Group I (control): rats were fed a standard diet for 24 weeks.

- Group II (positive control): rats were fed a standard diet and administrated garlic orally once daily at a dose of $250 \mathrm{mg} / \mathrm{kg}$ through a gastric tube for 24 weeks.

- Group III (HCD): rats were fed an HCD for 24 weeks.

- Group IV [HCD + garlic (G)]: rats were fed an HCD and given garlic orally once daily at a dose of $250 \mathrm{mg} / \mathrm{kg}$ through a gastric tube for 24 weeks. The dose of garlic was chosen based on previous study. ${ }^{25}$

By the end of the experiment, the rats were fasted for $12 \mathrm{~h}$ before they were euthanized using urethane anesthesia, and blood samples were collected and both eyes were enucleated after death. One eye from each rat was used for paraffin block preparation for light microscopic examination, and the other eye was prepared for ultrastructural examination.

\section{Biochemical parameters}

\section{Biochemical assessment of serum lipid profile}

Levels of serum TC, TG, LDL-C, and HDL-C were measured using quantitation kits (Biomed diagnostic, Egypt) following the manufacturer's protocol. The levels were assessed in $\mathrm{mg} / \mathrm{dL}$.

\section{Assessment of oxidative stress parameters}

Serum malondialdehyde (MDA) level was measured and expressed as $\mathrm{nmol} / \mathrm{mL}$ by measuring the formation of thiobarbituric acid reactive substances according to the manufacturer's instructions. $^{26}$

Serum superoxide dismutase (SOD) was measured and expressed as $\mathrm{U} / \mathrm{mL}{ }^{27}$

\section{Assessment of inflammatory mediators}

The plasma levels of IL- 6 and TNF- $\alpha$ were assessed using ELISA kits (RayBiotech, Inc., Norcross, GA, USA) and expressed as $\mathrm{pg} / \mathrm{mL}$.

\section{Light microscopic examination}

\section{Hematoxylin and eosin (H\&E) staining}

Sample tissues were dissected and immediately fixed in $10 \%$ neutral buffered formalin for $16 \mathrm{~h}$. Retinae were routinely 
processed and embedded in paraffin. Serial sections of 5- $\mu$ m thickness were obtained and stained with $\mathrm{H} \& \mathrm{E}$ to study the histological structure of the retina. ${ }^{28}$

\section{Immunohistochemical examination of caspase 3}

Immunohistochemistry was performed on the retinal paraffin sections. The sections were de-deparaffinized and hydrated. After pretreatment with antigen retrieval (DAKO) at $95^{\circ} \mathrm{C}$ for $15 \mathrm{~min}$, the sections were left to cool for $15 \mathrm{~min}$ at room temperature. Endogenous peroxidase activity was inhibited by incubating the slides in $0.3 \% \mathrm{H}_{2} \mathrm{O}_{2}$ for $30 \mathrm{~min}$. The sections were then incubated overnight at $4{ }^{\circ} \mathrm{C}$ with the primary antibodies. Caspase-3 rabbit polyclonal antibody (Lab Visions Corporation Laboratories, cata$\log$ number PA1-26426) was used at a concentration of 1:100. The secondary anti-rabbit antibody detection system (Envisions, Dako) was used for $20 \mathrm{~min}$ at room temperature. Finally, diaminobenzidine $0.05 \%$ (Dakopatts, Glostrup, Denmark) was applied as a chromogen at room temperature for $3 \mathrm{~min}$. Mayer's hematoxylin was used as a counterstain. Lastly, dehydration, clearing, and mounting were done. Tonsil was used as a positive control slide. Negative control slides were prepared by replacement of the primary antibodies with phosphate-buffered saline..$^{29}$

\section{Electron microscopic examination}

The retinae were fixed in $3 \%$ glutaraldehyde in $0.1 \mathrm{M}$ sodium cacodylate buffer ( $\mathrm{pH} 7.4$ ) overnight at $4{ }^{\circ} \mathrm{C}$ before being transferred to a solution containing $0.1 \mathrm{M}$ phosphate buffer. The cells were postfixed in S-collidine with $1 \%$ osmium tetroxide then dehydrated in graded ethanol before being transferred to propylene oxide and embedded in Epon 812.

Semi-thin sections were prepared, and toluidine blue $1 \%$ was applied on the selected part to be examined by a transmission electron microscope (TEM).

Uranyl acetate and lead citrate-stained ultrathin (75 nm thick) sections were examined and photographed ${ }^{30}$ by a JEOL TEM (100 CX; Tokyo, Japan) at the Faculty of Science, Alexandria University, Egypt.

\section{Histomorphometric study}

The area percent of Caspase-3 was measured using a CX31 light microscope (Olympus, tpkyo, Japan) connected with Leica
Qwin 500 image analyzer computer system (Leica, UK). Serial sections were obtained from the retina of each rat. 5 randomly selected sections from 5 rats/group were used. From each section, 5 different fields were selected and measured at 400x magnification. $^{31}$

\section{Statistical analysis}

The biochemical and histomorphometric data were expressed as mean \pm standard deviation and were statistically analyzed using SPSS version 22 (SPSS, Inc., Chicago, IL, USA). One-way analysis of variance followed by Tukey's post-hoc test was used to compare different groups with the control group. Results were considered significant when the $\mathrm{p}$-value was $<0.05 .{ }^{32}$

\section{Results}

\section{Biochemical results}

There was a significant increase in the levels of TC, TG, LDL$\mathrm{C}$, and decrease in the level of HDL-C in the HCD group as compared to both the control and $\mathrm{HCD}+\mathrm{G}$ groups. A non-significant difference was observed between the control and the HCD $+\mathrm{G}$ groups (Table 1).

The oxidative stress parameters revealed a significantly increased MDA level and a significant decrease in SOD in the HCD group as compared to the control group. A non-significant difference was observed between the control and the HCD + G groups (Table 2).

There was a statistically significant increase in the plasma levels of IL- 6 and TNF- $\alpha$ in the HCD group as compared to both the control and $\mathrm{HCD}+\mathrm{G}$ groups. A non-significant difference was observed between the control and the $\mathrm{HCD}+\mathrm{G}$ groups (Table 3 ).

\section{Light microscopic results}

\section{H\&E staining}

H\&E-stained sections of the retina of the control group showed the typical histological structure; the basal pigmented epithelium, the photoreceptor layer (PL) with its pale and regularly arranged

Table 1. Lipid profile parameters in the studied groups.

\begin{tabular}{|c|c|c|c|c|c|c|}
\hline & $\begin{array}{l}\text { Control group } \\
\text { (10 rats) }\end{array}$ & $\begin{array}{l}\text { Positive control group } \\
\text { (10 rats) }\end{array}$ & $\begin{array}{l}\text { HCD group } \\
\text { (10 rats) }\end{array}$ & $\begin{array}{l}\text { HCD + G group } \\
\text { (10 rats) }\end{array}$ & $\begin{array}{l}\text { ANOVA } \\
\text { p-value }\end{array}$ & $\begin{array}{l}\text { Tukey's } \\
\text { test p-value }\end{array}$ \\
\hline $\mathrm{TC}(\mathrm{mg} / \mathrm{dl})$ & $51.20 \pm 0.78$ & $53.41 \pm 1.01$ & $105.75 \pm 2.5$ & $53.11 \pm 0.95$ & $0.001^{*}$ & $\begin{array}{l}\mathrm{P} 1=0.47 \\
\mathrm{P} 2=0.001^{*} \\
\mathrm{P} 3=0.10 \\
\mathrm{P} 4=0.001^{*}\end{array}$ \\
\hline TG (mg/dl) & $51.36 \pm 1.10$ & $51.01 \pm 0.82$ & $68.15 \pm 1.2$ & $52.47 \pm 0.56$ & $0.001^{*}$ & $\begin{array}{l}\mathrm{P} 1=0.90 \\
\mathrm{P} 2=0.001^{*} \\
\mathrm{P} 3=0.16 \\
\mathrm{P} 4=0.001^{*}\end{array}$ \\
\hline LDL-c (mg/dl) & $16.46 \pm 1.01$ & $16.01 \pm 1.33$ & $48.34 \pm 1.7$ & $15.9 \pm 1.5$ & $0.001^{*}$ & $\begin{array}{l}\mathrm{P} 1=0.93 \\
\mathrm{P} 2=0.001^{*} \\
\mathrm{P} 3=0.89 \\
\mathrm{P} 4=0.001^{*}\end{array}$ \\
\hline HDL-c (mg/dl) & $31.29 \pm 1.05$ & $32.2 \pm 1.01$ & $21.96 \pm 0.84$ & $30.9 \pm 0.88$ & $0.001^{*}$ & $\begin{array}{l}\mathrm{P} 1=0.30 \\
\mathrm{P} 2=0.001 * \\
\mathrm{P} 3=0.69 \\
\mathrm{P} 4=0.001 *\end{array}$ \\
\hline
\end{tabular}

P1, control group (I) versus positive control group (II); P2, control group (I) versus HFD group (III); P3, control group (I) versus HCD + G group (IV); P4, HFD group (III) versus HCD + G group (IV); *statistically significant. 
outer segment and intensely stained inner segment; and the outer limiting membrane (OLM), which forms a continuous layer. A layer of closely packed nuclei of rods and cones form the outer nuclear layer (ONL). The outer plexiform layer (OPL) is a pale and thin synaptic layer followed by the inner nuclear layer (INL), which is thinner than the ONL and has nuclei of various sizes and density. The inner plexiform layer (IPL) has a reticular appearance similar to the OPL, but thicker. The ganglionic cell layer (GL) is formed by a single non-continuous layer of large cell bodies with rounded vesicular nuclei. The axons of the ganglion cells form the nerve fiber layer. A continuous layer of inner limiting membrane is seen (Figure 1 A1-3).

The retinae of the rats in the HCD group revealed disorganization of photoreceptors, areas of interruption in the OLM, thinning of OPL, and wide separation between the nuclei of the ONL and INL. Small darkly stained nuclei of ganglion cells with dilated and congested blood vessels were observed in the GL (Figure 1 B1-3).

The retinae of the rats in the $\mathrm{HCD}+\mathrm{G}$ group revealed obvious improvement of the histological features compared to that of the HCD group, and their features resembled almost those of the control group, apart from the slight separation of the nuclei of the INL (Figure 1 C1-3).

\section{Immunohistochemistry staining}

Caspase-3 immunoexpression was negative in all retinal layers of the control group (Figure 2A). Caspase-3 immunoexpression was positive in the OPL, ONL, INL, and GCL of the retinae of the HCD group (Figure 2B). Caspase-3 immunoexpression was slightly positive in the ONL and INL of the retinae of the $\mathrm{HCD}+\mathrm{G}$ group (Figure 2C).

\section{Morphometric results}

Statistical analysis of the areas showing immune reactions for caspase-3 showed that these were significantly increased in the HCD group as compared to both the control and HCD + G groups. However, a non-significant difference was observed between the control and HCD + G groups (Table 4).

\section{Electron microscopic results}

\section{Photoreceptor layer}

Retinae in the control group revealed regularly arranged outer and inner segments with slight spaces between the segments. The outer segments contained repeated and organized lamellar disks, and the inner segment contained elongated mitochondria with pre-

Table 2. Oxidative stress parameters in the studied groups.

\begin{tabular}{|c|c|c|c|c|c|c|}
\hline & $\begin{array}{l}\text { Control group } \\
\text { (10 rats) }\end{array}$ & $\begin{array}{l}\text { Positive control group } \\
\text { (10 rats) }\end{array}$ & $\begin{array}{l}\text { HCD group } \\
\text { (10 rats) }\end{array}$ & $\begin{array}{c}\text { HCD + G group } \\
\text { (10 rats) }\end{array}$ & $\begin{array}{l}\text { ANOVA } \\
\text { p-value }\end{array}$ & $\begin{array}{l}\text { Tukey's } \\
\text { test p-value }\end{array}$ \\
\hline $\operatorname{MDA}(\mathrm{nmol} / \mathrm{ml})$ & $4.97 \pm 0.25$ & $4.83 \pm 0.19$ & $8.53 \pm 0.17$ & $5.19 \pm 0.3$ & $0.001^{*}$ & $\begin{array}{l}\mathrm{P} 1=0.71 \\
\mathrm{P} 2=0.001^{*} \\
\mathrm{P} 3=0.32 \\
\mathrm{P} 4=0.001^{*}\end{array}$ \\
\hline $\mathrm{SOD}(\mathrm{U} / \mathrm{ml})$ & $174.56 \pm 2.55$ & $174.21 \pm 2.65$ & $138.63 \pm 2.30$ & $170.61 \pm 2.21$ & $0.001^{*}$ & $\begin{array}{l}\mathrm{P} 1=0.9 \\
\mathrm{P} 2=0.001 * \\
\mathrm{P} 3=0.44 \\
\mathrm{P} 4=0.001 *\end{array}$ \\
\hline
\end{tabular}

P1, control group (I) versus positive control group (II); P2, control group (I) versus HFD group (III); P3, control group (I) versus HCD + G group (IV); P4, HFD group (III) versus HCD + G group (IV); *statistically significant.

Table 3. Inflammatory cytokines levels in the studied groups.

\begin{tabular}{|c|c|c|c|c|c|c|}
\hline & $\begin{array}{l}\text { Control group } \\
\text { (10 rats) }\end{array}$ & $\begin{array}{l}\text { Positive control group } \\
\text { (10 rats) }\end{array}$ & $\begin{array}{l}\text { HCD group } \\
\text { (10 rats) }\end{array}$ & $\begin{array}{l}\text { HCD + G group } \\
\text { (10 rats) }\end{array}$ & $\begin{array}{l}\text { ANOVA } \\
\text { p-value }\end{array}$ & $\begin{array}{l}\text { Tukey's } \\
\text { test p-value }\end{array}$ \\
\hline IL-6 (pg /ml) & $180.15 \pm 3.06$ & $177.81 \pm 2.68$ & $420.87 \pm 4.34$ & $181.09 \pm 0.8$ & $<0.001^{*}$ & $\begin{array}{l}\mathrm{P} 1=0.47 \\
\mathrm{P} 2 \leq 0.001^{*} \\
\mathrm{P} 3=0.93 \\
\mathrm{P} 4 \leq 0.001^{*}\end{array}$ \\
\hline TNF- $\alpha(\mathrm{pg} / \mathrm{ml})$ & $73.9 \pm 1.0472 .53 \pm 1.05$ & $160.47 \pm 1.02$ & $74.64 \pm 1.11$ & $<0.001^{*}$ & & $\begin{array}{l}\mathrm{P} 1=0.11 \\
\mathrm{P} 2 \leq 0.001^{*} \\
\mathrm{P} 3=0.52 \\
\mathrm{P} 4 \leq 0.001^{*}\end{array}$ \\
\hline
\end{tabular}

P1, control group (I) versus positive control group (II); P2, control group (I) versus HFD group (III); P3, control group (I) versus HCD + G group (IV); P4, HFD group (III) versus HCD + G group (IV); *statistically significant.

Table 4. Area \% of caspase-3 immunohistochemical study in the studied groups.

\begin{tabular}{|c|c|c|c|c|c|c|}
\hline & $\begin{array}{l}\text { Control group } \\
\text { (10 rats) }\end{array}$ & $\begin{array}{l}\text { Positive control group } \\
\text { (10 rats) }\end{array}$ & $\begin{array}{l}\text { HCD group } \\
\text { (10 rats) }\end{array}$ & $\begin{array}{l}\mathrm{HCD}+\mathrm{G} \text { group } \\
\text { (10 rats) }\end{array}$ & $\begin{array}{l}\text { ANOVA } \\
\text { p-value }\end{array}$ & $\begin{array}{l}\text { Tukey's } \\
\text { test p-value }\end{array}$ \\
\hline Caspase-3 & 0 & 0 & $1.93 \pm 0.17$ & $0.47 \pm 0.03$ & $<0.001^{*}$ & $\begin{array}{l}\mathrm{P} 1=1 \\
\mathrm{P} 2=0.000^{*} \\
\mathrm{P} 3=0.000^{*} \\
\mathrm{P} 4=0.000^{* *}\end{array}$ \\
\hline
\end{tabular}

P1, control group (I) versus positive control group (II); P2, control group (I) versus HFD group (III); P3, control group (I) versus HCD + G group (IV); P4, HFD group (III) versus HCD + G group (IV); *statistically significant. 
served cristae, free ribosomes, and rough endoplasmic reticulum (rER) (Figure $3 \mathrm{~A}, \mathrm{~B}$ ). Retinae in the HCD group revealed widely separated outer and inner segments; the outer segments showed areas with degenerated lamellar disks, others showed irregularly arranged lamellae, and about a third without the outer segment membrane. The inner segment revealed swollen and irregularly arranged mitochondria without cristae and some vacuoles (Figure $3 \mathrm{C}-\mathrm{E}$ ). Retinae in the HCD $+\mathrm{G}$ group showed both the outer and inner segments with preserved ultrastructure, similar to that of the control group, except for the relatively wide spaces (Figure $3 \mathrm{~F}, \mathrm{G}$ ).

\section{Outer limiting membrane and outer nuclear layer}

The OLM and ONL in the control groups showed a continuous electron-dense OLM separating the PL from the ONL. The ONL was formed by the cell bodies of rods and cones and their nuclei. The nuclei of the rods were more numerous, smaller in size, and more condensed than those of the cones (Figure 4A). On the other side, the OLM and ONL in the HCD group exhibited an interrupted OLM. The ONL had small hyperchromatic nuclei with irregular nuclear membranes and wide separation of the cell bodies of the rods and cones (Figure 4 B1,B2). The OLM and ONL in the HCD
+ G group showed that the nuclei of the rods and cones were relatively similar to those of the control group with restoration of the OLM (Figure 4C).

\section{Outer plexiform layer}

The OPL in the control group revealed that the synapses between the axon terminal of the PL contained mitochondria with preserved cristae along with dendrites of bipolar nerve cells (Figure 5A). The OPL in the HCD group exhibited disrupted mitochondria without cristae and a relative decrease in the density of axon terminals of the PL (Figure 5B). The OPL in the HCD + G group appeared comparatively similar to that of the control group (Figure 5C).

\section{Inner nuclear layer}

The INL in the control group showed cell bodies of the following cells: bipolar cells with their large euchromatic nuclei surrounded by little cytoplasm, which contained mitochondria and rER; Müller cells with hyperchromatic nuclei and cytoplasmic processes that extended between the surrounding neurons; and he
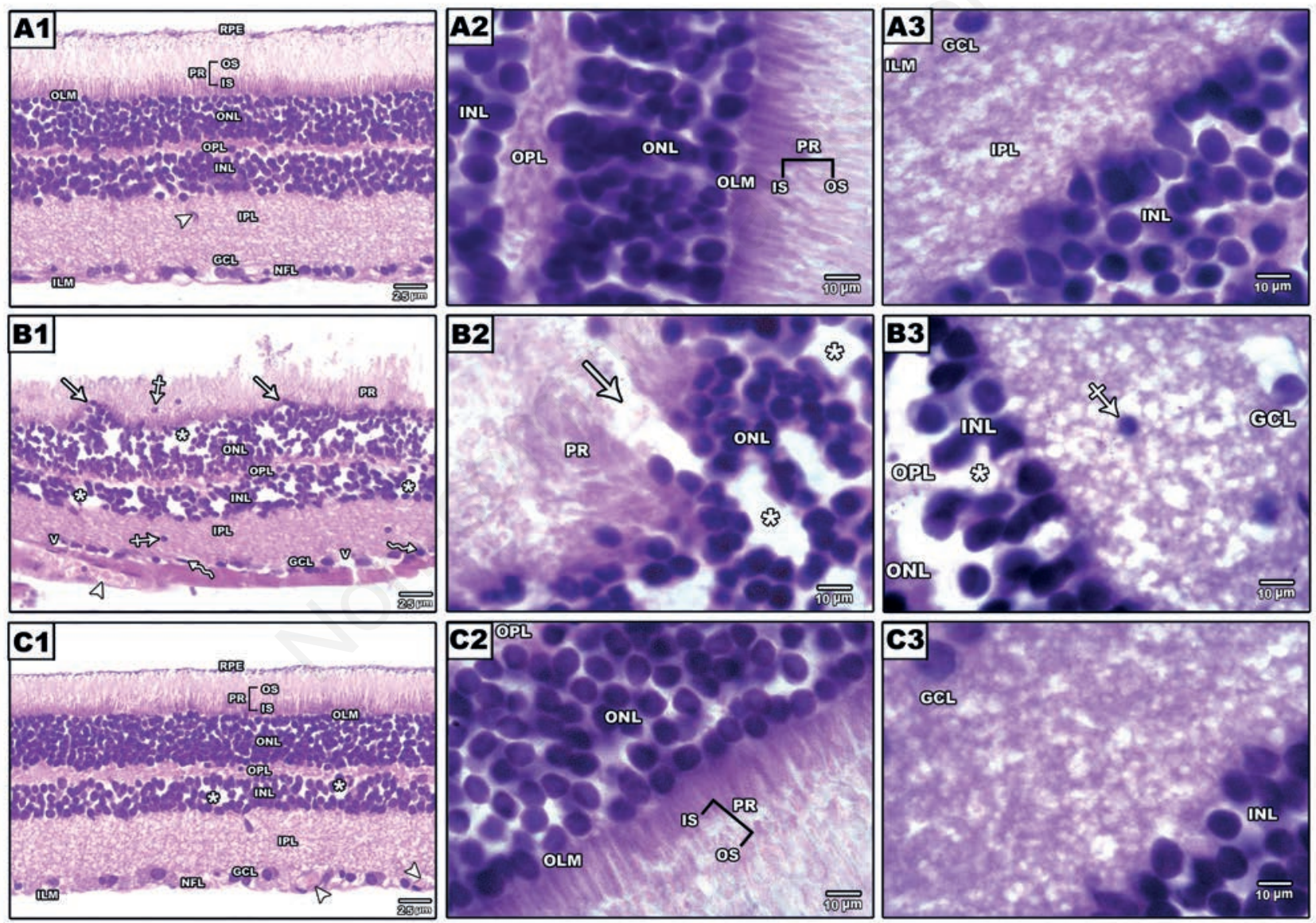

Figure 1. Photomicrographs of H\&E stained sections in the retina. A1-3) Control groups showing the normal histological structure of the ten layers of the retina; retinal pigment epithelial (RPE), the photoreceptor layer (PR) with its outer and inner segments (OS, IS), the outer limiting membrane (OLM), the outer nuclear layer (ONL), the outer plexiform layer (OPL), the inner nuclear layer (INL), the inner plexiform layer (IPL), the ganglion cell layer (GCL), nerve fiber layer (NFL) and the inner limiting membrane (ILM); fibers of Muller cells (arrowhead) are seen in the IPL layer. B1-3) HCD group showing an irregular arrangement of the processes of photoreceptors (PR); the OLM is interrupted (arrows); multiple spaces (stars) are obvious within both the ONL and INL; note that some nuclei of the ONL and INL (crossed arrows) are dislodged in the PR layer and IPL; the OPL looks precisely thin; the GCL revealing some cells with small darkly stained nuclei (zigzag arrows) and some vacuoles (V); congested blood vessels are seen in GCL (arrowhead). (C13) HCD + G group showing preserved photoreceptor layer; the histological appearance of the INL, IPL and GCL was similar to that of the control except few spaces $\left(^{*}\right)$ around cells of INL; note, normal blood vessel is seen in GCL (arrowheads). 

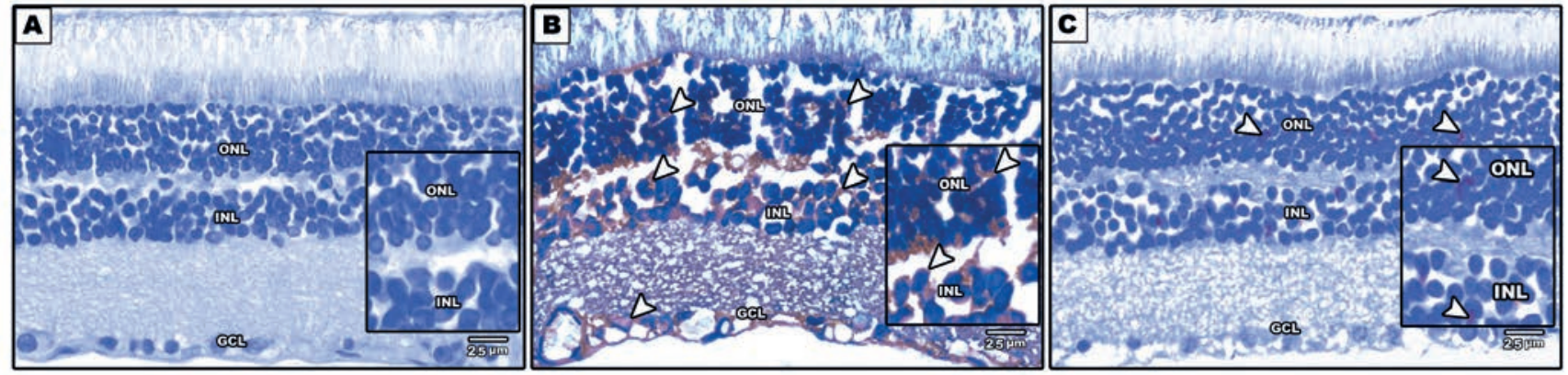

Figure 2. Photomicrographs of caspase-3 immunostained sections in the retina; A) the control groups showing negative immune reaction in all layers of the retina. B) HCD group showing positive immune reactions in the OPL and in cytoplasm of the cells of the ONL, INL and GCL (arrowheads). C) HCD + G group showing few positive cells in the ONL and INL (arrowhead).

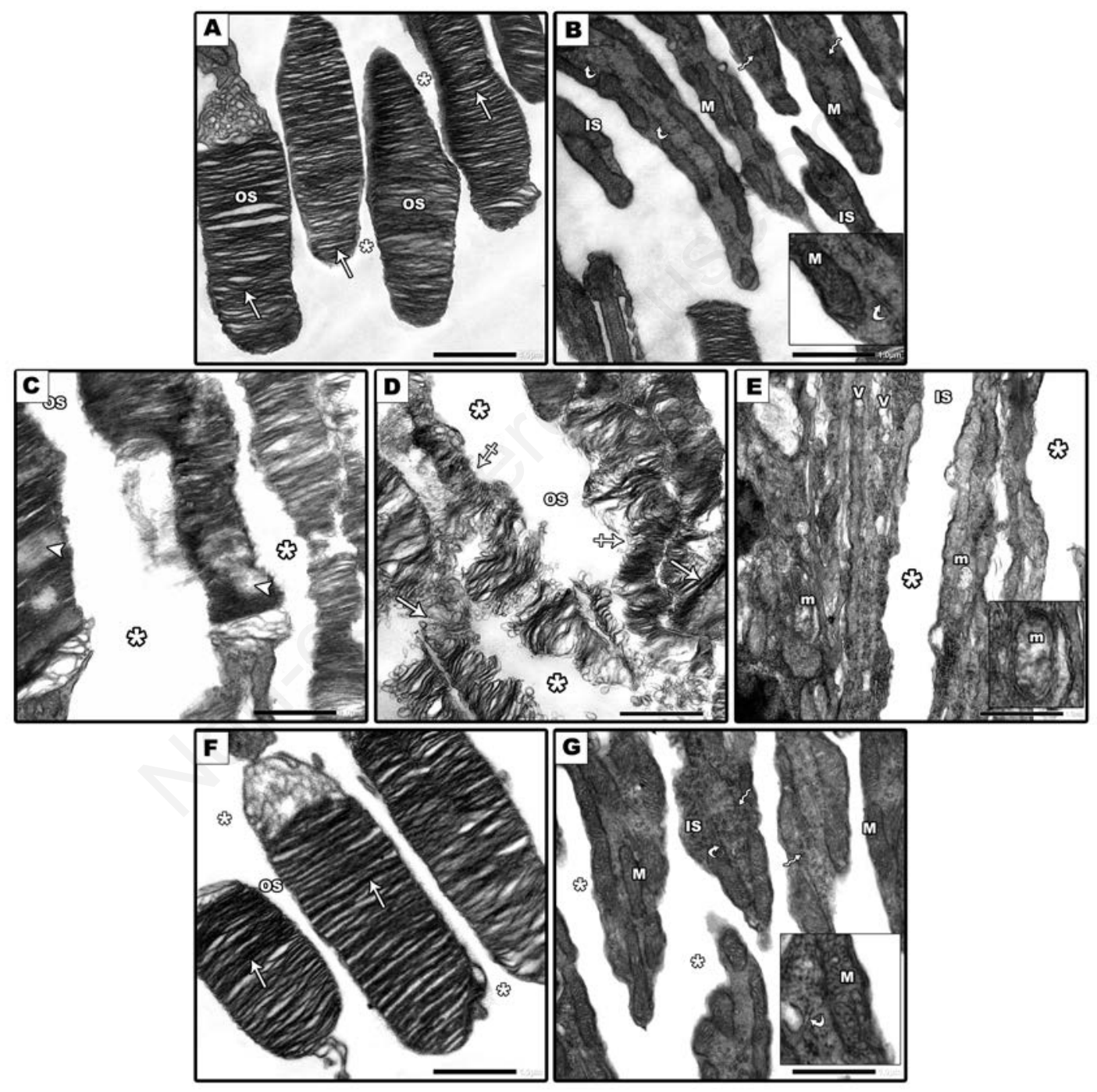

Figure 3. Electron micrographs of sections in the photoreceptors layer of the retina. A,B) Control group showing an elongated OS contains regularly arranged flattened horizontal lamellar discs (arrows); Tte IS containing elongated mitochondria (M) with preserved cristae, free ribosomes (zigzag arrows) and rER (curved arrows); minimal spaces are present between the segments (*). C-E) HCD group showing the OS with the area of degenerated discs (arrowheads) and other with lost OS membrane (crossed arrow) and irregular discs (arrows); the IS shows irregularly arranged swollen mitochondria (m) with lost cristae and some vacuoles (V); note that the spaces between the segments $\left(^{*}\right)$ are relatively widened. F,G) HCD + G group showing preserved ultrastructure of both OS and IS nearly similar to that of the control apart from relatively widened spaces $\left(^{*}\right)$ between the processes; the OS showing regularly arranged horizontal lamellar discs (arrow) and the IS showing intact mitochondria (M) with preserved cristae, free ribosomes (zigzag arrows) and rER (curved arrows). TEM: 8000x. 

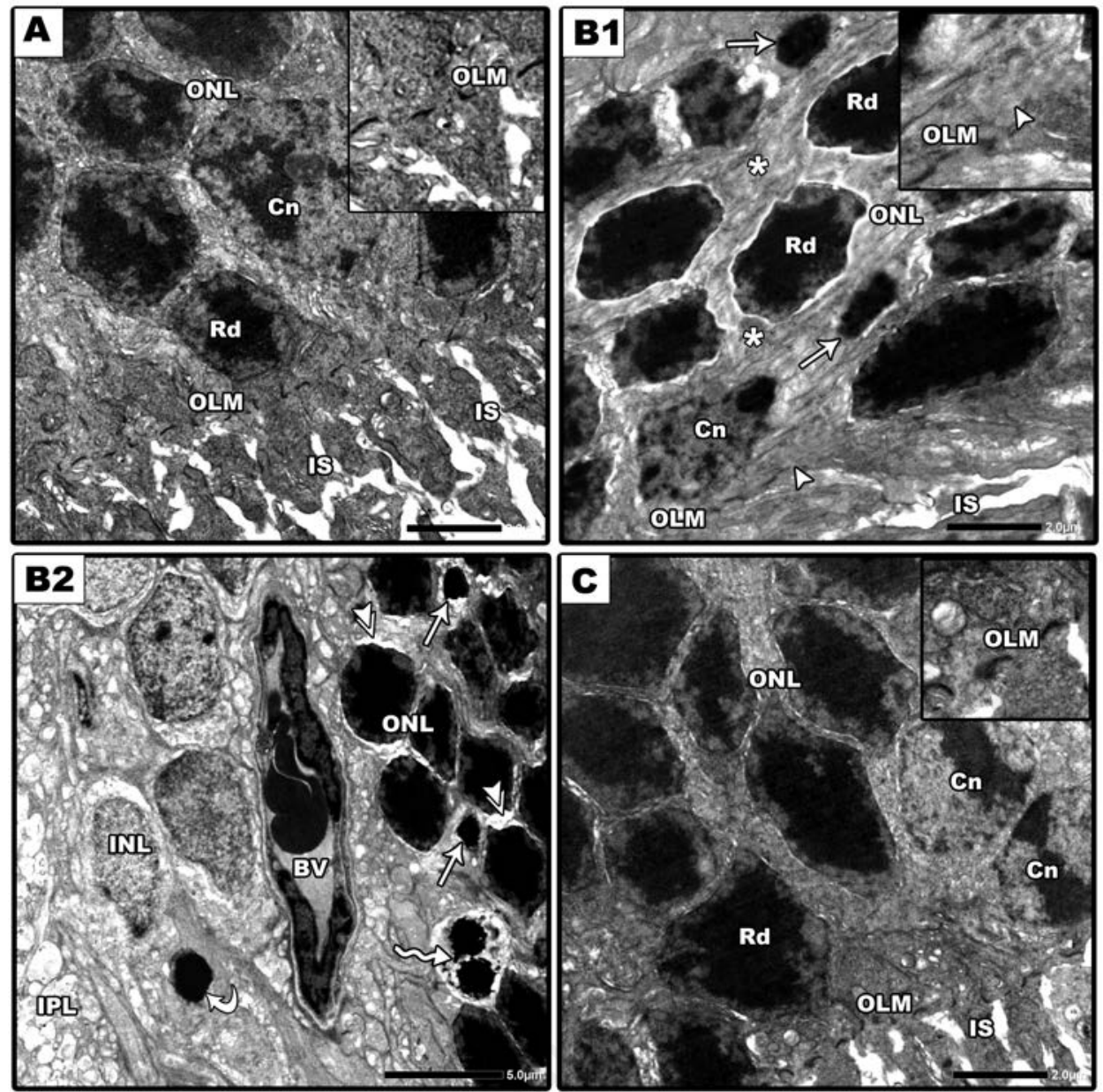

Figure 4. Electron photomicrographs of sections in the ONL (nuclei of rods and cones) and the OLM. A) Control group showing rods nuclei $(\mathrm{Rd})$ are smaller in size more electron-dense with large clumps of heterochromatin surrounded by a thin rim of cytoplasm; cones nuclei $(\mathrm{Cn})$ are larger less electron-dense with few clumps of heterochromatin; the nuclei of rods and cones are close together with minimal spaces; a continuous OLM and parts of IS are also observed. B1-2) HCD group showing some small pyknotic hyperchromatic nuclei (arrow), fragmentation of the nucleus (zigzag arrow) irregularity of both Rd and Cn nuclei with wide spaces between the cells $\left.{ }^{*}\right)$; note that interrupted OLM was observed (arrowhead), hyperchromatic nuclei in INL. C) HCD + G group showing ONL [rods (Rd) and cones $(\mathrm{Cn})$ nuclei] are relatively similar to the control group with the restoration of the OLM. TEM: 3000x.
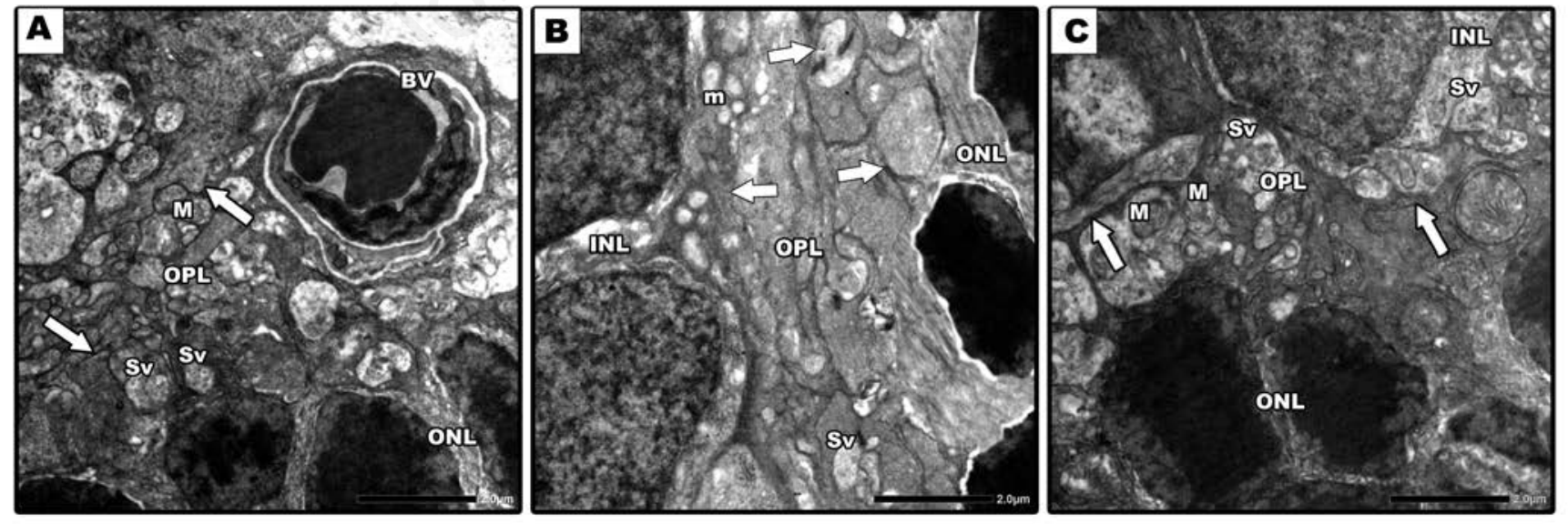

Figure 5. Electron photomicrographs of sections in the OPL. A) Control group showing the terminal synaptic process of the photoreceptors (thick arrows) containing mitochondria with preserved cristae (M) and synaptic vesicles (Sv); note that ONL and blood vessel (BV) are also seen. B) HCD group showing synaptic processes (thick arrows) between ONL and INL with disrupted mitochondria (m) and few synaptic vesicles (Sv). C) HCD + G group showing the restoration of the average thickness and density of the synaptic processes (thick arrows) between ONL and INL; the mitochondrial $(\mathrm{M})$ and synaptic vesicle $(\mathrm{Sv})$ ultrastructure are similar to that of the control group. TEM: 4000x. 
horizontal cells that had characteristic large nuclei with prominent nucleoli (Figure 6A). The INL in the HCD group exhibited numerous Müller cells. The bipolar cells were slightly shrunken, and there were areas of irregularities and disruption of nuclear membrane with widened perinuclear spaces. The cytoplasm contained swollen mitochondria without cristae, dilated rER, and multiple cytoplasmic vacuoles (Figure $6 \mathrm{~B}$ ). The INL in the $\mathrm{HCD}+\mathrm{G}$ group showed neuronal cell bodies that were relatively preserved, apart from few swollen mitochondria, dilated rER, and lysosomes in the cytoplasm of bipolar cells (Figure 6C).

\section{Inner plexiform layer}

The IPL in the control group showed the synapse between the axon terminals of the bipolar nerve cells and the dendrites of ganglion cells. The axon terminal showed mitochondria with pre- served cristae, neurofibrils, and synaptic vesicles (Figure 7A). The IPL in the HCD group showed a synaptic terminal containing mitochondria without cristae and relatively few synaptic vesicles (Figure 7B). The IPL in the HCD + G group showed synaptic terminals with preserved ultrastructural contents of mitochondria, neurofibrils, and synaptic vesicles (Figure 7C).

\section{Ganglionic cell layer}

The GL in the control group showed ganglion cells that had a large nucleus with a regular nuclear membrane. The cytoplasm showed multiple mitochondria with preserved cristae, free ribosomes, rER, Golgi apparatus, and few lysosomes (Figure 8A). The GL in the HCD group showed ganglion cells with irregular nuclear membranes and cytoplasm with numerous swollen mitochondria without cristae, dilated rER, and many vacuoles and lysosomes
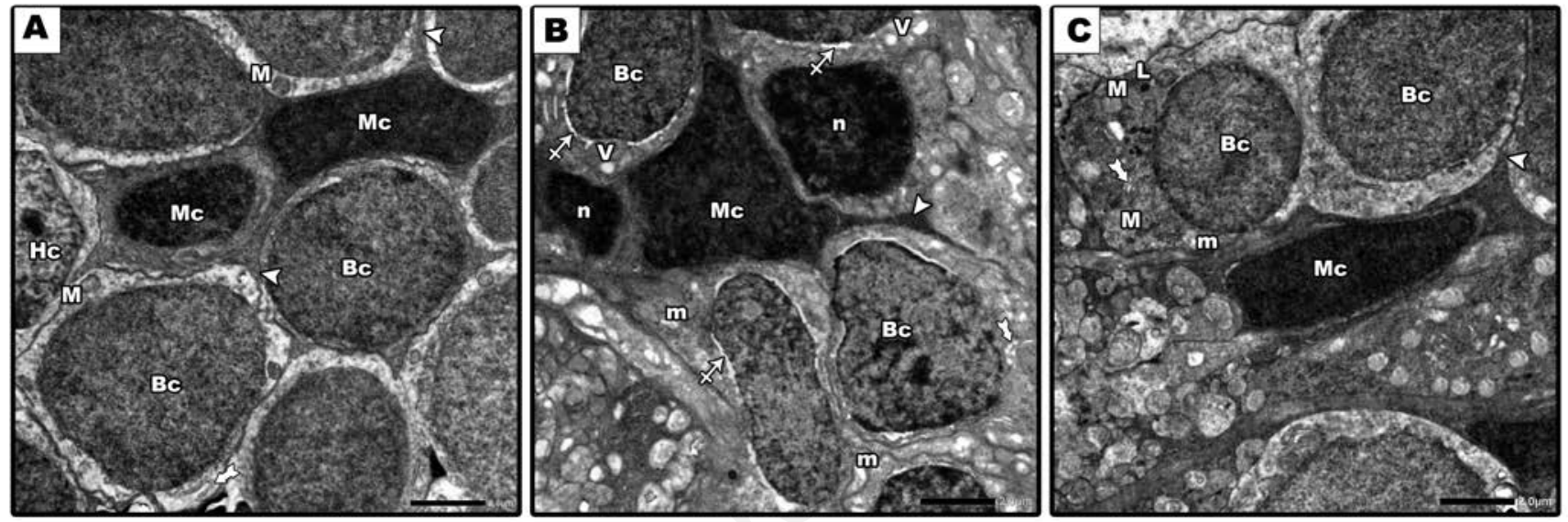

Figure 6. Electron photomicrographs of sections in the inner nuclear layer. A) The control group showing; Müller cells (Mc) with hyperchromatic nuclei and cytoplasmic processes intervened between the neurons (arrows heads), the bipolar cells (Bc) have large nuclei with dispersed chromatin and little cytoplasm containing mitochondria (M) and rER (tailed arrow) and the horizontal cells (Hc) have nuclei with noticeable nucleoli. B) HCD group showing many Muller cells with their characteristic nuclei (n); the bipolar cells (Bc) have wide perinuclear space (crossed arrow) slight shrinkage nuclei and areas of irregularity and disruption of nuclear membrane, their cytoplasm contains swollen mitochondria (m), dilated rER (tailed arrow), and cytoplasmic vacuoles (V). C) HCD + G group showing the cells of INL; Müller cells (Mc) with its cytoplasmic processes between the neurons (arrows head), bipolar cells (Bc) with large nuclei and little cytoplasm contain rER (tailed arrow), few lysosomes (L) and mitochondria with preserved cristae (M), apart from few disrupted ones (m). TEM: 2500x.
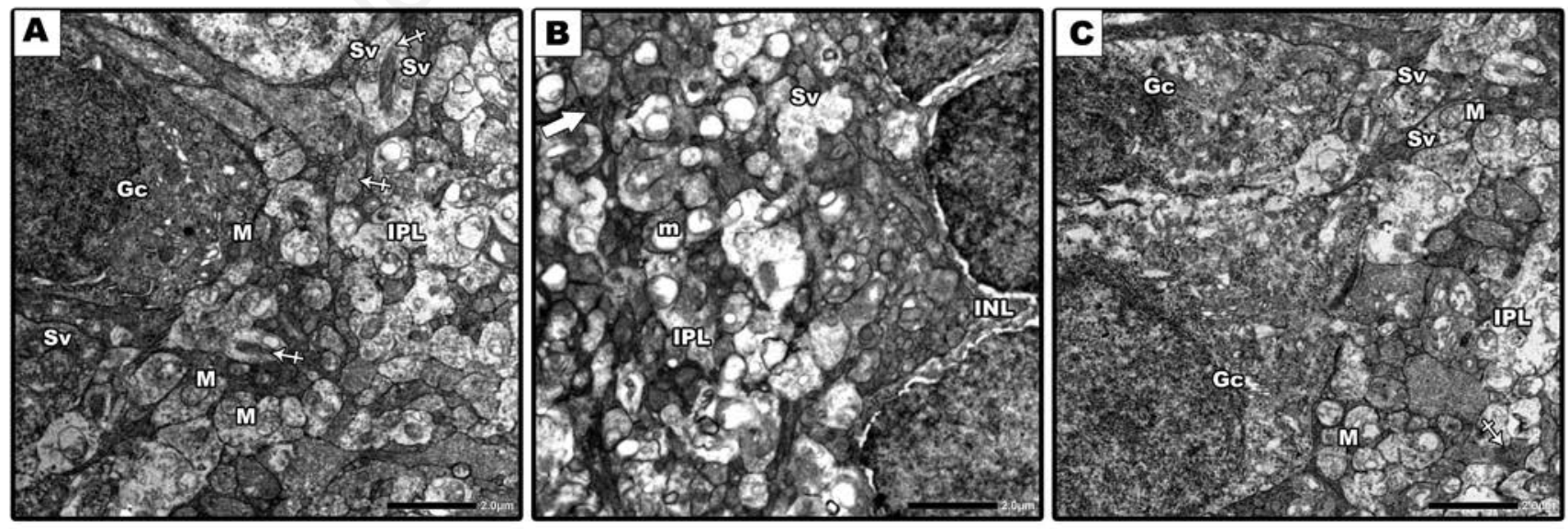

Figure 7. Electron micrographs of sections in the inner plexiform layer (IPL) between the Gc and the INL. A) Control group showing the synaptic terminals containing mitochondria $(\mathrm{M})$ with preserved cristae, neurofibrils (crossed arrows) and synaptic vesicles (Sv). B) HCD group showing synaptic processes (thick arrows) with swollen mitochondria (m) and few synaptic vesicles (Sv). C) HCD + G group showing synaptic terminals with relatively preserved mitochondria $(\mathrm{M})$, neurofibrils (crossed arrow) and synaptic vesicle (Sv). TEM: 3000x. 
(Figure $8 \mathrm{~B}$ ). The GL in the $\mathrm{HCD}+\mathrm{G}$ group showed ganglion cells with regular nuclear membranes with preserved ultrastructural contents (Figure 8C).

\section{Discussion}

Numerous researches have been conducted on the beneficial effects of garlic supplements on human and experimental animals. ${ }^{33,34}$ Garlic has been proven to have antioxidant, anti-apoptotic, antimicrobial, anticancer, and anti-inflammatory effects. However, the antioxidant, anti-apoptotic, and anti-inflammatory effects of garlic on the retina of individuals in a hypercholesteremic state remain unclear. In the present study, we tried to determine the role of garlic in ameliorating lipid and cholesterol oxidation, oxidative stress, and inflammation in addition to the histological changes in the retina of rats fed with an HCD.

The data of the current work demonstrated noticeable disorders in the lipid profile of rats fed with an HCD. This is shown by the significant increase in the levels of TC, TG, and LDL-C together with a decrease in the level of HDL-C, which is in agreement with previous research. ${ }^{35}$

MDA is produced by the degradation of polyunsaturated lipids due to ROS; therefore, it is used as a marker of oxidative stress in living cells. ${ }^{36} \mathrm{SOD}$ is an enzyme that degrades superoxide, hence its role as an antioxidant marker. ${ }^{27}$

It is known that oxidative stress occurs due to a disturbance in the balance between peroxidant and oxidant mechanisms. Hyperlipidemia has been proven to be associated with alterations in the physical properties of cellular membranes. This permits free radical outflow from the electron transport chain of the mitochondria, which result in peroxidation of cell membrane lipids, producing lipid peroxide radicals. ${ }^{37}$

A growing number of experimental data have been obtained, which support garlic as having strong antioxidant activity. ${ }^{18}$ Garlic has been proven to ameliorate oxidative stress, thereby preventing tissue damage. In this study, administration of garlic resulted in a noticeable improvement in the oxidative stress parameters, which could be due to the high polyphenol content in garlic. ${ }^{38}$ Allicin and alexin, which are the chief organosulfur constituents in garlic, has also been proven to possess the ability to neutralize numerous types of ROS. Hence, the antioxidant effects of garlic may relieve oxidative stress-related symptoms. ${ }^{18}$

A significant elevation of the plasma levels of inflammatory cytokines IL-6 and TNF- $\alpha$ were observed in the HCD group compared with the other groups. It has been reported that IL-6 and TNF- $\alpha$ are reliable indicators of hypercholesterolemia, even in people with no risk factors for the condition. ${ }^{39}$ These cytokines promote atherogenesis, and elevated plasma levels of TNF- $\alpha$ have been documented to increase the risk of heart disease and even heart failure. ${ }^{40}$

Generally, the high level of oxidative stress parameters and the release of ROS have been confirmed to promote the expression and synthesis of inflammatory cytokines. ${ }^{41}$ In the present study, serum levels of IL- 6 and TNF- $\alpha$ significantly decrease in the HCD $+\mathrm{G}$ group. Our results agree with those of a previous study, which documented that aged garlic extract could improve neuroinflammation by suppressing NO production and modifying the expression of several protein targets included in oxidative stress. ${ }^{42}$ This anti-neurotic effect of garlic could be due to its organic sulfur component, which has a stimulatory effect on microglia. ${ }^{43}$

The significant anti-inflammatory effects of garlic powder has been proven in cases of acute inflammation due to carrageeninduced leg and paw edema in rats and in chronic inflammation due to cotton pellet-induced dry granuloma weight. The antiinflammatory effect of garlic powder was comparable to that of piroxicam minus the adverse effects of non-steroidal anti-inflammatory drugs. ${ }^{44}$

Histological examination in our study revealed evidence of neurodegenerative changes in the retinae of the HCD group compared to those of the control group. This result is in agreement with that of Ban et al., ${ }^{45}$ who stated that increased levels of cholesterol or its metabolites may induce metabolic stress and lead to chronic lipotoxicity and neurodegenerative changes.

Oxidative stress could be a leading cause of cell death through apoptosis. It has been documented that one of the most consistent indicators for apoptosis in retinal tissue is the increased expression of caspase-3. The high level of expression of caspase-3 was asso-
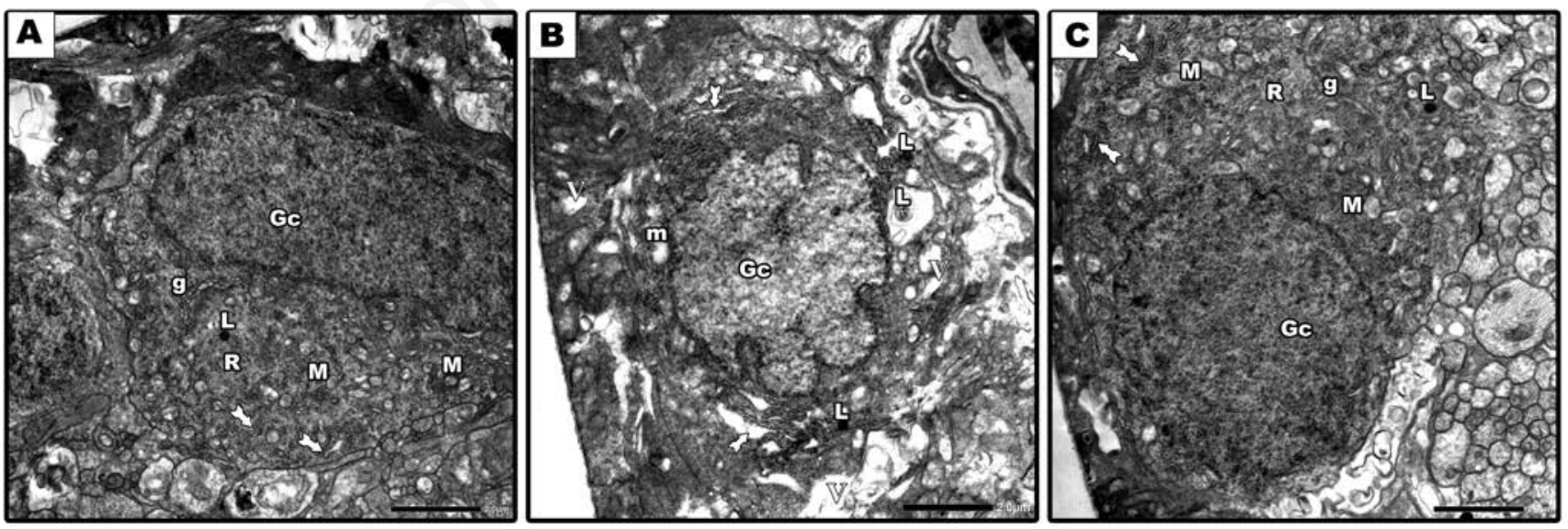

Figure 8. Electron micrographs of sections in the ganglionic cell layer. A) Control group showing Gc with regular nucleus, the cytoplasm contains well developed Golgi apparatus $(\mathrm{g})$, mitochondria $(\mathrm{M})$ with preserved cristae, ribosomes $(\mathrm{R})$, rough endoplasmic reticulum (tailed arrow) and lysosomes (L). B) HCD group showing Gc with irregular nuclear membrane. The cytoplasm contains swollen mitochondria (m), dilated rER (tailed arrow), cytoplasmic vacuoles $(\mathrm{V})$ and many lysosomes $(\mathrm{L}) . \mathrm{C}) \mathrm{HCD}+\mathrm{G}$ group showing preserved ultrastructure of Gc as in control, its cytoplasm contains well developed Golgi apparatus (g), intact mitochondria (M), ribosomes (R) and rough endoplasmic reticulum (tailed arrows). TEM: 3000x. 
ciated with the accelerated death of neurons. ${ }^{46}$

In the current study, mitochondrial integrity was evaluated via an ultrastructural study. Ultrastructural evaluation of mitochondrial integrity showed disrupted mitochondria without cristae in the photoreceptor cell layer and cytoplasm of the INL layer and GL. In addition, IHC expression of caspase- 3 was significantly elevated in the HCD group. It was reported that mitochondria are closely linked to the beginning of apoptosis. Increased levels of ROS could induce mitochondria to release cytochrome $\mathrm{C}$ with subsequent activation of caspase- $3 .{ }^{47}$

Besides the ultrastructural mitochondrial changes, small-sized hyperchromatic nuclei. Nuclear chromatin fragmentation and cytoplasmic vacuolation, which were observed in the INL, ONL, and GCL, provide proof for apoptosis and neurodegeneration of the retina. Apoptosis can be exaggerated by apoptogenic factors discharged upon the opening of the mitochondrial permeability transition pores. ${ }^{35}$

In addition to the disrupted mitochondria, the disorganization, wide separation, and vacuolations observed in the PL of the HCD group could indicate photoreceptors death, which was confirmed by the increased immunoexpression of caspase- 3 in the PL. A similar change in PL was detected after exposure of the retina to white LED light. ${ }^{48}$ These changes were related to oxidative stress and release of ROS from mitochondria, in addition to the release of cytochrome $\mathrm{C}$ from the mitochondrial matrix.

In the present work, a discontinuous or interrupted outer nuclear membrane was also observed in the retinae of the HCD group, which may have resulted from the disturbance of the tight junctions between the inner photoreceptor segments and the peripheral processes of Müller cells. ${ }^{49}$

In addition to the increased immunoexpression of caspase- 3 in the cytoplasm of ganglion cells, this study also revealed apoptotic changes in the GL in the form of irregular hyperchromatic nuclei, swollen mitochondria, numerous lysosomes, and dilated rER. These degenerative changes, along with those of the INL, may be secondary to photoreceptor degeneration with a consequent reduction in the feedback to postsynaptic bipolar and ganglion cells. ${ }^{50}$ Dilated, and congested capillaries were also seen in the GCL, which could have been due to oxidative stress and increased nitric components that caused venous dilatation. ${ }^{51}$

The findings of the present study provide a strong correlation between oxidative stress and the incidence of apoptosis and release of inflammatory cytokines in a hypercholesteremic state. It also provides evidence that garlic has strong antioxidant, anti-apoptotic, and anti-inflammatory properties. In this study, garlic has been proven to ameliorate the neurodegenerative changes in the neural retinae of hypercholesteremic rats. Further studies should be carried out to determine the vascular integrity in such cases.

\section{References}

1. Duan Y, Zeng L, Zheng C, Song B, Li F, Kong X, et al. Inflammatory links between high fat diets and diseases. Front Immunol 2018;9:2649.

2. Soliman GA. Dietary cholesterol and the lack of EIVdence in cardiovascular disease. Nutrients 2018;10:780.

3. Xu C, Li E, Xu Z, Su Y, Lu M, Qin JG, et al. Growth and stress axis responses to dietary cholesterol in Nile tilapia (Oreochromis niloticus) in brackish water. Front Physiol 2018;9:254..

4. Rao SR, FlieslerSJ. Cholesterol homeostasis in the vertebrate retina: biology and pathobiology. J Lipid Res 2021;62:100057.

5. Fourgeux C, Martine L, Gambert-Nicot S, Bron A, Garcher C, Bretillon L. Cholesterol and ocular pathologies: focus on the role of cholesterol-24S-hydroxylase in cholesterol homeostasis. OCL 2015;22:D204.

6. Ramachandra Rao S, Fliesler SJ. Cholesterol homeostasis in the vertebrate retina: biology and pathobiology. J Lipid Res 2021;62:100057.

7. Opoku S, Gan Y, Fu W, Chen D, Addo-Yobo E, Trofimovitch $\mathrm{D}$, et al. Prevalence and risk factors for dyslipidemia among adults in rural and urban China: findings from the China National Stroke Screening and prevention project (CNSSPP). BMC Public Health 2019;19:1500.

8. Vance JE. Dysregulation of cholesterol balance in the brain: contribution to neurodegenerative diseases. Dis Model Mech 2012;5:746-55.

9. Yücel I, Akar Y, Yücel G, Ciftçioglu MA, Keleş N, Aslan M. Effect of hypercholesterolemia on inducible nitric oxide synthase expression in a rat model of elevated intraocular pressure. Vision Res 2005;45:1107-14.

10. Shang A, Cao SY, Xu XY, Gan RY, Tang GY, Corke H, et al. Bioactive compounds and biological functions of garlic (Allium sativum L.). Foods 2019;8:246.

11. Ried K, Fakler P. Potential of garlic (Allium sativum) in lowering high blood pressure: mechanisms of action and clinical relevance. Integr Blood Press Control 2014;7:71-82.

12. Aquila G, Marracino L, Martino V, Calabria D, Campo G, Caliceti $\mathrm{C}$, et al. The use of nutraceuticals to counteract atherosclerosis: The role of the notch pathway. Oxid Med Cell Longev 2019;2019:5470470.

13. Kim TM, Kim KH, Jo JH, Park J, Kwon YS, Yang JH. Hepatoprotective effect of a novel lactic acid-fermented garlic extract functional food product against acute liver injury. Food Sci Nutr 2020;8:1012-9.

14. Moss JW, Ramji DP. Nutraceutical therapies for atherosclerosis. Nat Rev Cardiol 2016;13:513-32.

15. Liu J, Ji F, Chen FM, Guo W, Yang ML, Huang SX, et al. Determination of garlic phenolic compounds using supercritical fluid extraction coupled to supercritical fluid chromatography/tandem mass spectrometry. J Pharm Biomed Anal 2018;159:513-23.

16. Kang JS, Kim SO, Kim GY, Hwang HJ, Kim BW, Chang YC, et al. An exploration of the antioxidant effects of garlic saponins in mouse-derived $\mathrm{C} 2 \mathrm{C} 12$ myoblasts. Int J Mol Med 2016;37:149-56.

17. Rabe SZT, Ghazanfari T, Siadat Z, Rastin M, Rabe SZT, Mahmoudi M. Anti-inflammatory effect of garlic 14-kDa protein on LPS-stimulated-J774A.1 macrophages. Immunopharmacol Immunotoxicol 2015;37:158-64.

18. Leung HH, Yau YF, Leung KS, Lee YY, Oger C, Durand T, et al. Garlic supplementation modified enzymatic Omega-6 polyunsaturated fatty acid oxidation in mild hypercholesterolemia. Eur J Lipid Sci Technol 2019;121:1900069.

19. Jung ES, Park SH, Choi EK, Ryu BH, Park BH, Kim DS, et al. Reduction of blood lipid parameters by a 12 -wk supplementation of aged black garlic: a randomized controlled trial. Nutrition 2014;30:1034-9.

20. Matsuura H. Saponins in garlic as modifiers of the risk of cardiovascular disease. J Nutr 2001;131:1000S-5S.

21. Sun YE, Wang W, Qin J. Anti-hyperlipidemia of garlic by reducing the level of total cholesterol and low-density lipoprotein: A meta-analysis. Medicine (Baltimore) 2018;97:e0255.

22. Cleome ViscosaLinn UR. A natural source of pharmaceuticals and pesticides. Int J Green Pharm 2015;9:71.

23. Chinellato A, Ragazzi E, Petrelli L, Paro M, Mironov A, Aliev G. Effect of cholesterol-supplemented diet in heritable hyperlipidemic Yoshida rats: functional and morphological characterization of thoracic aorta. Atherosclerosis 1994;106:51-63. 
24. Aliev G, Shi J, Perry G, Friedland RP, Lamanna JC. Decreased constitutive nitric oxide synthase, but increased inducible nitric oxide synthase and endothelin-1 immunoreactivity in aortic endothelial cells of donryu rats on a cholesterol-enriched diet. Anat Rec 2000;260:16-25.

25. Supakul L, Pintana H, Apaijai N, Chattipakorn S, Shinlapawittayatorn K, Chattipakorn N. Protective effects of garlic extract on cardiac function, heart rate variability, and cardiac mitochondria in obese insulin-resistant rats. Eur J Nutr 2014;53:919-28.

26. Meng Q, Shi D, Feng J, Su Y, Long Y, He S, et al. Hypercholesterolemia up-regulates the expression of intermedin and its receptor components in the aorta of rats IVa inducing the oxidative stress. Ann Clin Lab Sci 2016;46:234-40.

27. Ściskalska M, Ołdakowska M, Marek G, Milnerowicz H. Changes in the activity and concentration of superoxide dismutase isoenzymes $(\mathrm{Cu} / \mathrm{Zn} \mathrm{SOD}, \mathrm{MnSOD})$ in the blood of healthy subjects and patients with acute pancreatitis. Antioxidants (Basel) 2020;9:948.

28. Bancroft JD, Layton C. The hematoxylins and eosin. In: K.S. Suvarna, C. Layton, J.D. Bancroft, editors. Bancroft's theory and practice of histological techniques e-book. London: Elsevier; 2018. pp. 26-138.

29. Kamel Ismail ZM, Morcos MA, Eldin Mohammad MD, Gamal Aboulkhair A. Enhancement of neural stem cells after induction of depression in male albino rats (a histological \& immunohistochemical study). Int J Stem Cells 2014;7:70-8.

30. Dykstra MJ, Reuss LE. Staining methods for semi thins and ultra-thins. In: M.J. Dykstra, L.E. Reuss, editors. Biological electron microscopy, theory, techniques and troubleshooting. Kluwer Academic Publishers/Plenum Press; 2003. pp. 175-96.

31. Arafat EA, Shabaan DA. The possible neuroprotective role of grape seed extract on the histopathological changes of the cerebellar cortex of rats prenatally exposed to valproic acid: animal model of autism. Acta Histochem 2019;121:841-51.

32. Emsley R, Dunn G, White IR. Mediation and moderation of treatment effects in randomised controlled trials of complex interventions. Stat Methods Med Res 2010;19:237-70.

33. Mahmoud R, Aziza A, Marghani B, Eltaysh R. Influence of ginger and garlic supplementation on growth performance, whole body composition and oxidative stress in the muscles of Nile tilapia (O. niloticus). Adv Anim Vet Sci 2019;7:397-404.

34. Ohtani M, Nishimura T. Sulfur-containing amino acids in aged garlic extract inhibit inflammation in human gingival epithelial cells by suppressing intercellular adhesion molecule-1 expression and IL-6 secretion. Biomed Rep 2020;12:99-108.

35. Fernández-Navarro J, Aldea P, de Hoz R, Salazar JJ, Ramírez AI, Rojas B, et al. Neuroprotective effects of low-dose statins in the retinal ultrastructure of hypercholesterolemic rabbits. PLoS One 2016;11:e0154800.

36. Del Rio D, Stewart AJ, Pellegrini NA. Review of recent studies on malondialdehyde and biological marker of oxidative stress. Nutr Metab Cardiovasc Dis 2005;15:316-28.

37. Farnaghi S, Prasadam I, Cai G, Friis T, Du Z, Crawford R,. et al. Protective effects of mitochondria-targeted antioxidants and statins on cholesterol-induced osteoarthritis. FASEB J 2017;31:356-67

38. Bozin B, Mimica-Dukic N, Samojlik I, Goran A, Igic R. Phenolics as antioxidants in garlic (Allium sativum L., Alliaceae). Food Chem 2008;111:925-9.

39. Tsoupras A, Lordan R, Zabetakis I. Inflammation, not cholesterol, is a cause of chronic disease. Nutrients 2018;10:604.

40. Ramji DP, Davies TS. Cytokines in atherosclerosis: key players in all stages of disease and promising therapeutic targets. Cytokine Growth Factor Rev 2015;26:673-85.

41. Famurewa AC, Ejezie AJ, Ugwu-Ejezie CS, Ikekpeazu EJ, Ejezie FE. Antioxidant and anti-inflammatory mechanisms of polyphenols isolated from virgin coconut oil attenuate cadmium-induced oxidative stress-mediated nephrotoxicity and inflammation in rats. J Appl Biomed 2018;16:281-8.

42. Zhou H, Qu Z, Mossine VV, Nknolise DL, Li JL, Chen ZZ, et al. Proteomic analysis of the effects of aged garlic extract and its FruArg component on lipopolysaccharide-induced neuroinflammatory response in microglial cells. PLoS One 2014;9:e113531.

43. Shang A, Cao SY, Xu XY, Gan RY, Tang GY, Corke H, et al. Bioactive compounds and biological functions of garlic (Allium sativum L.). Foods 2019;8:246-9.

44. Jayanthi MK, Dhar M, Jayanthi M. Anti-inflammatory effects of Allium sativum (garlic) in experimental rats. Biomedicine 2011;31:84-9.

45. Ban N, Lee TJ, Sene A, Dong Z, Santeford A, Lin JB, et al. Disrupted cholesterol metabolism promotes age-related photoreceptor neurodegeneration. J Lipid Res 2018;59:1414-23.

46. Pizzino G, Irrera N, Cucinotta M, Pallio G, Mannino F, Arcoraci V, et al. Oxidative stress: harms and benefits for human health. Oxid Med Cell Longev 2017;2017:8416763.

47. Sánchez-Rivera FJ, Ryan J, Soto-Feliciano YM, Clare Beytagh MC, Xuan L, Feldser DM, et al. Mitochondrial apoptotic priming is a key determinant of cell fate upon p53 restoration. Proc Natl Acad Sci USA 2021;118:e2019740118.

48. Farag E, Yousry M, Omar A. Histological study on the detrimental influences of white LED light on the retina of adult albino rat and the potential effect of simultaneous nicotine administration with highlighting their possible mechanisms. Egypt J Histol 2017;40:328-44.

49. Hippert C, Graca AB, Barber AC, West EL, Smith AJ, Ali RR, Pearson RA. Müller glia activation in response to inherited retinal degeneration is highly varied and disease specific. PLoS One 2015;10:e0120415.

50. El-Sayyad HI, Ali DA, Hanafy ME. Fish-oil supplementation improves retinal injury induced by diabetes and hypercholesterolemia in male Wistar rats. Egypt J Basic Appl Sci 2020;7:100-15.

51. Nian S, Lo ACY, Mi Y, Ren K, Yang D. Neurovascular unit in diabetic retinopathy: pathophysiological roles and potential therapeutical targets. Eye Vis (Lond) 2021;8:15.

Received for publication: 4 September 2021. Accepted for publication: 1 December2021.

This work is licensed under a Creative Commons Attribution-NonCommercial 4.0 International License (CC BY-NC 4.0).

(C) Copyright: the Author(s), 2021

Licensee PAGEPress, Italy

European Journal of Histochemistry 2021; 65:3322

doi:10.4081/ejh.2021.3322 